\title{
Radiological Assessment of Surgical Treatment of Distal Radius Fractures among Patients at an Academic Center in Jeddah \\ Orjwan Anas Abulaban ${ }^{1}$, Abdulrahman Ihsan Alrifai ${ }^{1}$, Salma Ayman Almosallam ${ }^{1}$, Aseel Anas Abulaban ${ }^{1}$, Amre Sami Hamdi ${ }^{1}$ \\ ${ }^{1}$ College of Medicine, King Abdulaziz University, Jeddah, Saudi Arabia \\ Corresponding author: Orjwan Abulaban, Phone number: 00966553739474, E-mail: orjwan.abulaban@gmail.com
}

\begin{abstract}
Background: Distal radius fractures (DRFs) are mainly treated by surgery; however, there is no strong evidence to establish the superiority of one modality over another.

Aim: To determine the most efficient surgical procedure in terms of restoring anatomical angles in DRFs.

Methods: This retrospective study was conducted at King Abdulaziz University Hospital, Jeddah between 2010 and 2016. It involved 31 patients with DRF treated surgically. All patients were assessed pre-and post-operatively to measure radial height (RH), radial inclination(RI),ulnar variance (UV) and volar tilt (VT) on posteroanterior and lateral radiographs. The Shapiro-Wilk test was performed to determine the normality of measurements.

Results: Pre-operative variables, including (RH), (RI), (VT), and (UV), were not significantly different among patients in all treatment groups. In group 1 (closed reduction with $\mathrm{K}$-wire, external fixation, or both), all the pre- and post-treatment variables were significantly different $(p<0.05)$, except (UV) $(p=0.867)$. Conversely, the difference between pre- and post-measurement variables in group 2 (open reduction with plate and screw) was significantly high ( $\mathrm{p}<0.05$ ). Further, group 3 (open reduction with $\mathrm{K}$-wire plus plate and screws) and group 4 (open reduction with K-wire plus plate and screws in combination with external fixation) showed no significant difference $(\mathrm{p}>0.05)$.
\end{abstract}

Conclusion: Open reduction with plate and screws was highly effective in the management of DRFs. However, additional studies are needed to establish an effective management for these fractures.

Keywords: Distal radial fracture, open reduction, closed reduction, radial inclination.

\section{INTRODUCTION}

Distal radius fractures (DRFs) are the most common fracture among all age groups, particularly in pediatric and elderly populations ${ }^{(1)}$ due to the high rate of falls and prevalence of osteoporosis in these age groups ${ }^{(2)}$. DRFs account for more than 640,000 of all fractures reported annually in the United States ${ }^{(3)}$.

It is well-known that DRFs need steady reduction and internal or external fixation ${ }^{(4)}$. If not properly aligned and fixed, fractures lead mostly to post-traumatic arthritis 1 . Although DRFs are among the most common injuries treated by orthopedics, the treatment options are variable and remain a topic of debate ${ }^{(5,6)}$.

In addition to cast immobilization for minimal displacement, ${ }^{(4)}$ there are several treatment modalities for unstable DRF restoration, including closed reduction with either internal fixation (IF) or external fixation (EF) and open reduction with internal fixation (ORIF) ${ }^{(7,8)}$. For several years, cast immobilization has been the mainstay of treatment ${ }^{(9)}$. Nevertheless, an unsystematic trial showed that ORIF was superior to casting regarding the prompt ability to move the wrist. Additionally, ORIF minimized the period needed to regain proper range of motion $(\mathrm{ROM})$ and enabled better anatomical reassembling of the fragments and articular surface than superior casting ${ }^{(7,10-13)}$. This finding was reported by other investigators who found that ORIF was associated with a better radiological outcome when volar locking plate fixation was used ${ }^{(9)}$. However, there have been many significant complications reported with ORIF, such as tendon rupture, carpal tunnel syndrome, and high rates of infections ${ }^{(7,10)}$.

While many studies have shown acceptable anatomical and functional results with EF, this surgical modality increases the risk of displacements in up to $50 \%$ of patients, and it is associated with multiple complications, such as pin tract infection, cosmetic deformity, and nerve injury ${ }^{(8,10,14)}$. On the other hand, some investigators suggested that EF had remarkably refined the radiological measurements (radial length and dorsal tilt) in correlation to casting 15. Although IF (using K-wire) has the advantage of being reasonable, easy to perform, and minimally invasive, (7) the introduction of variable angle locking plates has led to a decrease in the use of this fixation method ${ }^{(12)}$.

Most authors report the relationship between radiographic variables and their influence on the final outcome in patients with DRFs ${ }^{(16)}$. Several studies proved that in patients with DRFs, it was possible to restore function more effectively with anatomical restoration than other solutions (16). Further, the restoration of volar angulation, radial length, and radial inclination were reported to be essential for good functional outcomes at the wrist ${ }^{(12)}$.

There is no consensus on the management of DRFs among orthopedic and hand surgeons9. However, the main goal of treatment is to reduce the DRF anatomically and restore the patient's level of functioning ${ }^{(9)}$. Despite the importance of radiological 
outcomes of DRFs, a paucity of evidence remains for establishing the best surgical technique in terms of the restoration of anatomical angles. Therefore, this study aims to establish the best surgical technique to restore the anatomical angle following surgery for DRFs and compare the radiological outcomes of different surgical techniques.

\section{PATIENTS AND METHODS}

From 2010 to 2016, a total of 31 adult patients with DRFs were treated at King Abdulaziz University Hospital (KAUH), Jeddah, Saudi Arabia. Ethical approval was obtained from the Institutional Ethics Committee at KAUH (reference number, IEC KMC MLR 03-16/45). We retrospectively analyzed the data of patients who sustained a DRF and were treated with closed reduction with IF fixation alone or combined with $\mathrm{EF}$ or with open reduction with plate and screws alone or in combination with $\mathrm{K}$-wire or EF.

An Excel sheet was used to collect demographic data, including gender, age, and nationality; body mass index (BMI); side of injury; and the approach and surgical technique used. All data collected were stored in a secure file inside the hospital where only the main author could access it.

The approaches were divided into closed reduction, dorsal, and volar. Surgical techniques were categorized into four groups: group 1 (closed reduction with K-wire, external fixation, or both), group 2 (open reduction with plate and screws), group 3 (open reduction with $\mathrm{K}$-wire plus plate and screw), and group 4 (open reduction with K-wire plus plate and screws in combination with external fixation).

To evaluate the fracture type and anatomical restoration after fixation, the study design largely depended on plain radiographs taken during the patient's first visit to the clinic prior to surgery and the follow-up visit after surgery (post-operative). The radiological parameters measured on posterioranterior (PA) and true lateral radiographs were radial height $(\mathrm{RH})$, radial inclination (RI), ulnar variance (UV), and volar tilt (VT).

The reference range for $\mathrm{RH}$ is $8-18$ $\mathrm{mm}, 17-20$ and it was measured as the distance between two lines perpendicular to the long axis of the radius - one drawn at the tip of the radial styloid, and another drawn at the distal ulnar articular surface (Figure 1A)21, 22.
Ulnar variance is the vertical distance between two lines both perpendicular to the long axis of the radius. It ranges between -2 and $4 \mathrm{~mm}$ 17-20.

In the lateral view, the VT of the distal radius articular surface was measured. It ranges between 0 and 28 degrees (Figure 1B) 17-21.

The RH or radial length and RI were determined on the PA view. The RI ranges between 13 and 30 degrees, 17-20 and it was determined by measuring the angle between a line drawn through the radial styloid process and the medial corner of the lunate facet and a line drawn perpendicular to the long axis of the radius (Figure 1C) 21,22.
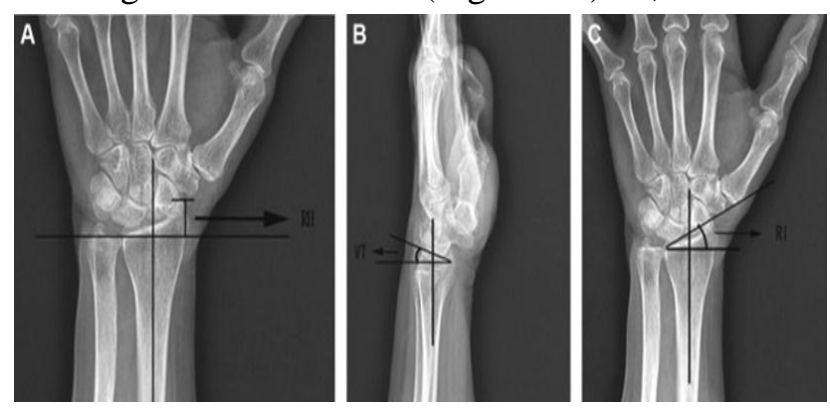

Figure (1): Method used to measure radial height (A), volar tilt (B), and radial inclination (C).

The angles were measured pre- and postoperatively or during the follow-up, depending on the availability of the patients' records. To determine whether pre- and post-operative measurements were significantly different between the four treatment groups, the Shapiro-Wilk test was used to test the normality of the study's preand post-operative sample variables. The test revealed that all variables were not normally distributed. Therefore, the parametric test ANOVA was used for normally distributed variables while the non-parametric test the Kruskal-Wallis test was used for non-normally distributed variables.

Significant differences were evaluated by a one-way measure ANOVA test. A p-value less than 0.05 was considered statistically significant.

\section{RESULTS}

A total of 31 patients (including 19 males) were willing to participate in this study. The patients were aged between 20 and 88 years. Eleven righthand and 20 left-hand fractures were documented (Table 1). 
Table (1): Summary of patients' demographic data

\begin{tabular}{|l|l|c|c|}
\hline \multicolumn{2}{|c|}{ Variables } & Frequency & Percent \\
\hline \multirow{2}{*}{ Gender } & Male & 19 & 61.3 \\
& Female & 12 & 38.7 \\
\hline \multirow{2}{*}{ Nationality } & Saudi & 14 & 45.2 \\
& Non-Saudi & 17 & 54.8 \\
\hline \multirow{4}{*}{ Age } & $18-30$ years & 4 & 12.9 \\
& 31-40 years & 3 & 9.7 \\
& 41-50 years & 6 & 19.4 \\
& $\geq 51$ years & 18 & 58.1 \\
\hline \multirow{2}{*}{ Side } & Right hand & 11 & 35.5 \\
& Left hand & 20 & 64.5 \\
\hline \multirow{3}{*}{ BMI } & Underweight & 1 & 3.6 \\
& Normal weight & 4 & 14.3 \\
& Overweight & 12 & 42.9 \\
& Obese & 11 & 39.3 \\
\hline
\end{tabular}

BMI, body mass index.

A comparison of the surgical modalities and radiological parameters before surgery (preoperative) showed that none of the pre-operative variables was significantly different between the four treatment groups (Table 2).

Table (2): Comparison of pre-operative radiographic measurements in the different groups

\begin{tabular}{|c|c|c|c|c|c|}
\hline \multirow[b]{2}{*}{ Measurements } & \multicolumn{5}{|c|}{ Treatment Groups } \\
\hline & $\begin{array}{c}\text { Group 1 } \\
(n=8)\end{array}$ & $\begin{array}{c}\text { Group 2 } \\
(n=16)\end{array}$ & $\begin{array}{c}\text { Group } 3 \\
(n=4)\end{array}$ & $\begin{array}{c}\text { Group } 4 \\
(n=3)\end{array}$ & $\begin{array}{c}\text { p- } \\
\text { value }\end{array}$ \\
\hline Radial height (mm) & 3.40 & 7.50 & 5.65 & 3.00 & 0.605 \\
\hline $\begin{array}{l}\text { Radial inclination } \\
\text { (degrees) }\end{array}$ & 12.60 & 18.50 & 11.30 & 14.60 & 0.831 \\
\hline Volar tilt (degrees) & 23.00 & 18.60 & 2.90 & 30.70 & 0.189 \\
\hline $\begin{array}{l}\text { Ulnar variance } \\
(\mathrm{mm})\end{array}$ & 2.60 & 2.70 & 0.00 & 4.80 & 0.305 \\
\hline
\end{tabular}

Reference range: Radial height (11-12 mm), radial inclination (22-23 degrees), volar tilt (11-12 degrees), ulnar variance (normal, $-2-2 \mathrm{~mm}$ ).

Group definitions: Group 1, closed reduction with $\mathrm{K}$ wire, external fixation, or both; group 2, open reduction with plate and screws; group 3, open reduction with $\mathrm{K}$ wire plus plate and screws; and group 4, open reduction with $\mathrm{K}$ wire plus plate and screws in combination with external fixation.

Table 3 shows a summary of ANOVA comparison of radiological parameters (RI and VT) between the treatment groups post-surgery.

Table (3): ANOVA comparison of post-operative radial inclination and volar tilt in the treatment groups 1 .

\begin{tabular}{|c|c|c|c|c|c|}
\hline \multirow{2}{*}{ Measurements } & \multicolumn{5}{|c|}{ Treatment Groups } \\
\cline { 2 - 7 } & $\begin{array}{c}\text { Group 1 } \\
(\mathbf{n = 8 )}\end{array}$ & $\begin{array}{c}\text { Group 2 } \\
(\mathbf{n = 1 6})\end{array}$ & $\begin{array}{c}\text { Group 3 } \\
(\mathbf{n = 4 )}\end{array}$ & $\begin{array}{c}\text { Group 4 } \\
(\mathbf{n = 3})\end{array}$ & $\begin{array}{c}\text { p- } \\
\text { value }\end{array}$ \\
\hline $\begin{array}{c}\text { Radial } \\
\text { inclination } \\
\text { (degrees) }\end{array}$ & 22.18 & 25.78 & 23.98 & 20.33 & 0.084 \\
\hline $\begin{array}{c}\text { Volar tilt } \\
\text { (degrees) }\end{array}$ & $9.19(6.10)$ & $(3.98)$ & $(2.25)$ & $(2.61)$ & \\
\hline
\end{tabular}

1 Data are presented as mean (standard deviation) unless otherwise specified.

Reference range: Radial inclination (22-23 degrees), volar tilt (11-12 degrees).

Group definitions: Group 1, closed reduction with $\mathrm{K}$ wire, external fixation, or both; group 2, open reduction with plate and screws; group 3, open reduction with $\mathrm{K}$ wire plus plate and screws; and group 4 , open reduction with $\mathrm{K}$ wire plus plate and screws in combination with external fixation.

Table 4 depicts a summary of the KruskalWallis comparison of radiological parameters $(\mathrm{RH}$ and UV) between the treatment groups. None of the post-surgery variables were significantly different between the four treatment groups (tables 3 and 4).

Table (4): Kruskal-Wallis comparison of radial height and ulnar variance in the treatment groups.

\begin{tabular}{|c|c|c|c|c|c|}
\hline \multirow{3}{*}{ Measurements } & \multicolumn{5}{|c|}{ Treatment Groups } \\
\hline & $\begin{array}{c}\text { Group 1 } \\
(n=8)\end{array}$ & $\begin{array}{c}\text { Group 2 } \\
(\mathrm{n}=16)\end{array}$ & $\begin{array}{c}\text { Group 3 } \\
(n=4)\end{array}$ & $\begin{array}{c}\text { Group } 4 \\
(n=3)\end{array}$ & \\
\hline & $\begin{array}{c}\text { 50th } \\
\text { (Median) }\end{array}$ & $\begin{array}{c}\text { 50th } \\
\text { (Median) }\end{array}$ & \begin{tabular}{|c|} 
50th \\
(Median)
\end{tabular} & $\begin{array}{c}\text { 50th } \\
\text { (Median) }\end{array}$ & value \\
\hline Radial height & 11.65 & 12.80 & 14.25 & 12.40 & 0.700 \\
\hline Ulnar variance & 0.00 & 0.00 & -0.68 & 0.00 & 0.867 \\
\hline
\end{tabular}

Reference range: Radial height $(11-12 \mathrm{~mm})$, ulnar variance (normal, -2-2 mm).

Group definitions: Group 1, closed reduction with $\mathrm{K}$ wire, external fixation, or both; group 2, open reduction with plate and screws; group 3, open reduction with $\mathrm{K}$ wire plus plate and screws; and group 4, open reduction with $\mathrm{K}$ wire plus plate and screws in combination with external fixation.

As shown in tables 5 and 6 , not all paired variables were the same for each treatment group. The mean differences between pre- and post-surgery measurements were as follows:

In group 1, the difference between the mean pre- and post-operative RH was significant $(\mathrm{p}=0.024)$. Similarly, a significant difference was found between the mean pre- and post-operative RI $(\mathrm{p}=0.061)$, as well as the pre- and post-operative VT $(\mathrm{p}=0.033)$. Conversely, the difference between pre- and postoperative UV was not significant ( $\mathrm{p}=0.363$ ).

In group 2, the difference between the mean pre- and post-operative RI was significant ( $\mathrm{p}<0.001$ ). Similarly, a significant difference was found between the mean pre- and post-operative RI ( $\mathrm{p}<0.001$ ), pre- and post-operative volar tilt $(\mathrm{p}=0.045)$, and pre- and postoperative ulnar variance $(\mathrm{p}=0.009)$. 
In group 3, the difference between the mean preand post-operative $\mathrm{RH}(\mathrm{p}=0.180), \mathrm{RI}(\mathrm{p}=0.180), \mathrm{VT}(\mathrm{p}$ $=0.180)$, and $\mathrm{UV}(\mathrm{p}=0.317)$ were not significant.

In group 4, no statistically significant difference was found between the mean pre- and post-operative RH ( $\mathrm{p}=0.180), \mathrm{RI}(\mathrm{p}=0.655)$, VT ( $\mathrm{p}$ $=0.180)$, and UV $(\mathrm{p}=0.180)$.

Table (5): Paired sample comparison of radiological pre- and post-surgery measurements in group 1 and group 2 patients

\begin{tabular}{|l|l|c|c|c|}
\hline $\begin{array}{c}\text { Treatment } \\
\text { Groups }\end{array}$ & Measurements & Pre-Surgery & $\begin{array}{c}\text { Post- } \\
\text { Surgery }\end{array}$ & \multirow{2}{*}{$\begin{array}{c}\text { p- } \\
\text { value }\end{array}$} \\
\cline { 3 - 4 } & & Mean (SD) & Mean (SD) & \\
\hline \multirow{4}{*}{$\begin{array}{l}\text { Group 1 } \\
(\mathrm{n}=7)\end{array}$} & RH (mm) & $5.84(5.67)$ & $11.30(4.02)$ & 0.024 \\
\cline { 2 - 4 } & RI (degrees) & $13.88(9.22)$ & $20.92(4.99)$ & 0.061 \\
\cline { 2 - 4 } & VT (degrees) & $23.23(17.75)$ & $7.79(5.01)$ & 0.033 \\
\cline { 2 - 4 } & UV (mm) & $2.20(3.88)$ & $0.47(2.82)$ & 0.363 \\
\hline \multirow{3}{*}{$\begin{array}{l}\text { Group 2 } \\
(n=13)\end{array}$} & RH (mm) & $6.88(3.24)$ & $13.35(3.04)$ & 0.000 \\
\cline { 2 - 5 } & RI (degrees) & $17.94(5.54)$ & $26.09(4.24)$ & 0.000 \\
\cline { 2 - 5 } & VT (degrees) & $16.43(10.59)$ & $10.54(7.09)$ & 0.045 \\
\cline { 2 - 4 } & UV (mm) & $2.53(2.53)$ & $-0.03(2.23)$ & 0.009 \\
\hline
\end{tabular}

Abbreviations: BMI, body mass index; RH, radial height; RI, radial inclination; $\mathrm{SD}$, standard deviation; UV, ulnar variance; VT, volar tilt.

Reference range: Radial height (11-12 mm), radial inclination (22-23 degrees), volar tilt (11-12 degrees), ulnar variance (normal, $-2-2 \mathrm{~mm}$ ).

Group definitions: Group 1, closed reduction with $\mathrm{K}$ wire, external fixation, or both; group 2, open reduction with plate and screws.

Table (6): Wilcoxon paired sample comparison of pre- and post-surgery measurements in group 3 and group 4 patients.

\begin{tabular}{|c|c|c|c|c|}
\hline \multirow{2}{*}{$\begin{array}{c}\text { Treatment } \\
\text { Groups }\end{array}$} & \multirow{2}{*}{ Measurements } & $\begin{array}{c}\text { Pre- } \\
\text { Surgery }\end{array}$ & $\begin{array}{c}\text { Post- } \\
\text { Surgery }\end{array}$ & \multirow{2}{*}{$\begin{array}{c}\text { P- } \\
\text { value }\end{array}$} \\
\hline & & $\begin{array}{c}\text { 50th } \\
\text { (Median) }\end{array}$ & $\begin{array}{c}\text { 50th } \\
\text { (Median) }\end{array}$ & \\
\hline \multirow{4}{*}{$\begin{array}{l}\text { Group } 3 \\
(n=4)\end{array}$} & $\mathrm{RH}$ & 5.65 & 14.25 & 0.180 \\
\hline & RI & 11.30 & 23.10 & 0.180 \\
\hline & VT & 2.90 & 14.00 & 0.180 \\
\hline & $\overline{U V}$ & 0.00 & -0.68 & 0.317 \\
\hline \multirow{4}{*}{$\begin{array}{l}\text { Group } 4 \\
(n=3)\end{array}$} & $\mathrm{RH}$ & 3.00 & 12.40 & 0.180 \\
\hline & RI & 14.60 & 19.70 & 0.655 \\
\hline & VT & 30.70 & 7.00 & 0.180 \\
\hline & UV & 4.80 & 0.00 & 0.180 \\
\hline
\end{tabular}

Abbreviations: BMI, body mass index; RH, radial height; RI, radial inclination; SD, standard deviation; UV, ulnar variance; VT, volar tilt.

Reference range: Radial height (11 to $12 \mathrm{~mm}$ ), radial inclination (22 to 23 degrees), volar tilt (11 to 12 degrees), ulnar variance (normal, -2 to $2 \mathrm{~mm}$ ).

Group definitions: Group 3, open reduction with $\mathrm{K}$ wire plus plate and screws; group 4 , open reduction with $\mathrm{K}$ wire plus plate and screws in combination with external fixation.

\section{DISCUSSION}

This study was conducted to find the most suitable surgical modality for treating DRFs in terms of radiological outcomes. The efficacy of different surgical modalities was studied in 31 patients treated at KAUH. The post-operative radiological measurements for group 2 patients (ORIF) was significant compared to those of patients in the other three groups.

In a study conducted by Kotian et al. ${ }^{(9)}$ it was established that volar locking plate fixation successfully maintained fracture reduction during the post-operative monitoring period. Our results are in line with those of Kotian et al. who showed that ORIF was the most effective treatment to maintain reduction and radiological measurements in DRFs because UV and VT were effectively restored. It is also well established that UV and VT are the most critical radiological variables for effective treatment of DRFs ${ }^{(16,23)}$.

Other researchers reported that ORIF offered the most favorable anatomical restoration, ${ }^{(14)}$ with patients being less likely to develop arthritis in subsequent years. Furthermore, in our study, patients who had closed reduction with IF, or EF, or both (Group 1) displayed a significant difference in RH, RI, and VT. However, we did not find a significant variation between mean UV measurements, which is a critical factor for assessing treatment efficacy in DRFs ${ }^{(16,23)}$. This finding is consistent with those of other investigators who did not find a significant difference in UV in patients who had EF or IF.24 Similarly, in another study, ${ }^{(15)}$ the authors showed a significant improvement in dorsal tilt and $\mathrm{RH}$ in fractures treated with EF. Conversely, Yang et al. ${ }^{(25)}$ posited that $\mathrm{EF}$ and IF (K-wire) were undesirable and perhaps not the ideal choice for all DRFs.

Another important index that can be used to assess the best treatment modality is ROM, including flexion, extension, pronation, supination, radial deviation, and ulnar deviation ${ }^{(8)}$.

We acknowledge that our study has limitations. First, it has all the shortcomings inherent to retrospective studies. Thus, the accuracy of our data may be questionable due to missing information in patients' medical records. Second, only 31 patients were enrolled in our study. The relatively small number of patients may be due to the stringent selection of patients at our tertiary care center, which typically accepts cases with complex fractures. That being the case, the findings of the present study cannot be generalized to patients managed in other 
centers. Despite that, we believe data from the present study can be used for comparison in future studies. Therefore, future research is warranted to investigate these surgical modalities in DRF management, confirm our findings, and test clinical applications. Furthermore, all aspects, including indications, advantages, and complications, as well as radiological and functional outcomes, should be considered in the assessment of different surgical modalities.

\section{CONCLUSION}

ORIF with plate and screws was the most effective surgical modality for the management of DRFs in terms of radiological restoration. However, additional studies are needed to establish an effective modality for the management of these fractures.

\section{REFERENCES}

1. Nellans KW, Kowalski E, Chung KC (2012): The Epidemiology of Distal Radius Fractures. Hand Clin.,28(2):113-25.

2. Harris IA, Naylor JM, Lawson A, Buchbinder R, Ivers R, Balogh Z et al. (2017): A combined randomized and observational study of surgery for fractures in the distal radius in the elderly (CROSSFIRE) a study protocol. BMJ Open., 7(6): e016100.

3. Jo YH, Lee BG, Kim HS, Kim JH, Lee CH, Kim SJ et al. (2018): Incidence and Seasonal Variation of Distal Radius Fractures in Korea: A Population-based Study. J Korean Med Sci., 33(7):e48.

4. Abramo A, Kopylov P, Geijer M, Tägil M (2009): Open reduction and internal fixation compared to closed reduction and external fixation in distal radial fractures. Acta Orthop.,80(4):478-85.

5. Qiu WJ, Li YF, Ji YH, Xu W, Zhu XD, Tang XZ et al. (2015): The comparative risk of developing postoperative complications in patients with distal radius fractures following different treatment modalities. Sci Rep.,5:15318.

6. Machado DG, da Cruz Cerqueira SA, de Lima AF, de Mathias MB, Aramburu JPG, Rodarte RRP (2016): Statistical analysis on the concordance of the radiological evaluation of fractures of the distal radius subjected to traction. Rev Bras Ortop.,51(1):11-5.
7. Franceschi F, Franceschetti E, Paciotti M, Cancilleri F, Maffulli N, Denaro D (2015): Volar locking plates versus K-wire/pin fixation for the treatment of distal radial fractures: a systematic review and quantitative synthesis. Br Med Bull.,115(1):91-110.

8. Zhang Q, Liu F, Xiao Z, Li Z, Wang B, Dong $J$ et al. (2016): Internal Versus External Fixation for the Treatment of Distal Radial Fractures. Medicine (Baltimore),95(9):e2945.

9. Kotian P, Mudiganty S, Annappa R, Austine J (2017): Radiological Outcomes of Distal Radius Fractures Managed with 2.7mm Volar Locking Plate Fixation-A Retrospective Analysis. J Clin Diagn Res JCDR., 11(1):RC09-RC12.

10. Sun Z, Rui Y, Song $X J$, Wei $X$ (2014): Minimally invasive plate osteosynthesis for distal radius fractures. Indian $\mathbf{J}$ Orthop., 48(1):20.

11. Park JH, Hagopian J, Ilyas AM (2010): Variable-angle locking screw volar plating of distal radius fractures. Hand Clin., 26(3):373-380.

12. Khatri K, Sharma V, Farooque K, Tiwari V (2016): Surgical Treatment of Unstable Distal Radius Fractures with a Volar Variable-Angle Locking Plate: Clinical and Radiological Outcomes. Arch Trauma Res.,5(2):e25174.

13. Bartl C, Stengel D, Bruckner T, Rossion I, Luntz S, Seiler C et al. (2011): Open reduction and internal fixation versus casting for highly comminuted and intra-articular fractures of the distal radius (ORCHID): protocol for a randomized clinical multi-center trial. Trials., 12:84.

14. Pradhan U, Agrawal A, Prasad P, Chauhan V, Maheshwari R, Juyal A (2013): ClinicoRadiological and functional outcome after surgical fixation of intraarticular fractures of distal end of radius by external fixator versus locked volar plate: A prospective randomised study. IOSR J Dent Med Sci.,6:20-26.

15. Vargaonkar $G$ (2014): Distal end radius fractures: evaluation of results of various treatments and assessment of treatment choice. Chin J Traumatol Zhonghua Chuang Shang Za Zhi.,17(4):214-9. 
16. Dario P, Matteo G, Carolina C, Marco G, Cristina D, Daniele F et al. (2014): Is it really necessary to restore radial anatomic parameters after distal radius fractures? Injury.,45 Suppl 6:S21-6.

17. Jupiter JB (1991): Fractures of the distal end of the radius. $\mathrm{J}$ Bone Joint Surg Am.,73(3):461-9.

18. Fernandez DL, Jupiter JB (2016): Fractures of the Distal Radius: A Practical Approach to Management. 2nd ed. Berlin: Springer-Verlag. https://books.google.com.sa/books?hl=en\&lr= \&id $=\mathrm{Oq} 4$ updeNrNcC\&oi=fnd\&pg=PP9\&dq $=\mathrm{F}$ ernandez+DL,+Jupiter+JB.+Fractures+of + the + Distal+Radius: $+\mathrm{A}+$ Practical+Approach + to $+\mathrm{M}$ anagement.+2nd+ed.+Berlin:+Springer-

Verlag\% 3B + 2012.++ \&ots= jxFlR14 Wsm\&sig =-CdGojkLO 0cBnimfh ZOuPvi9KM k\&redir_ esc=y\# v=onepage $\& q \& \mathrm{f}=$ false

19. Trumble T, Budoff JE, Cornwall $R$ (2006): Hand, Elbow \& Shoulder: Core Knowledge in Orthopaedics. Maryland Heights: Mosby. http://www.liveconferences.com/images/Courses /PDFSample/Trumble\%20Core\%20Ortho.pdf.

20. Ng CY, McQueen MM (2011): What are the radiological predictors of functional outcome following fractures of the distal radius? J Bone Joint Surg Br.,93(2):145-50.
21. Cai L, Zhu S, Du S, Lin W, Wang T, Lu D et al. (2015): The relationship between radiographic parameters and clinical outcome of distal radius fractures in elderly patients. Orthop Traumatol Surg Res.,101(7):827-31.

22. Masood K (2016): Radiological and Clinical Outcome of Distal Radial Fractures Managed by Variable Angle $2.4 \mathrm{~mm}$ Titanium Volar Plate. Orthop Muscular Syst.,5:222.

23. Arora R, Gabl M, Gschwentner M, Deml C, Krappinger D, Lutz M (2009): A comparative study of clinical and radiologic outcomes of unstable colles type distal radius fractures in patients older than 70 years: nonoperative treatment versus volar locking plating. J Orthop Trauma,23(4):237-42.

24. Jeudy J, Steiger V, Boyer $P$, Cronier $P$, Bizot P, Massin P (2012): Treatment of complex fractures of the distal radius: a prospective randomised comparison of external fixation "versus" locked volar plating. Injury, 43(2):174-9.

25. Yang M, Zhu S, Gao Z, An G (2014): Outcomes of open distal radius fractures managed with bridging external fixator and Kirschner-wire fixation. Zhonghua Yi Xue Za Zhi.,94(22):1729-32. 